\title{
Protocolo de extracción y procesamiento de células madre adultas del tejidlo adiposo abdominal: coordenadas del cirujano plástico en la investigación traslacional \\ Protocol of extraction and processing of adult stem cells from abdominal adipose tissue: coordenates of the plastic surgeon in translational researching
}

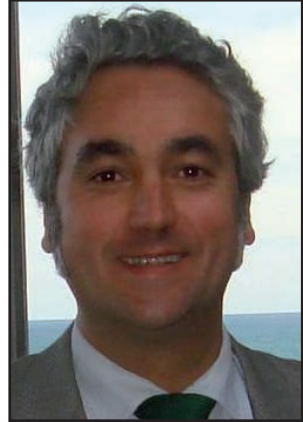

Serna-Cuéllar, E.

\section{Serna-Cuéllar, E.*, Santamaría-Solís, L.**}

Resumen

La terapia basada en células madre adultas constituye la forma de tratamiento más innovadora para la regeneración de los tejidos patológicos, ausentes o deficitarios; también de relleno estético apropiado para variedad de indicaciones cosméticas y reconstructivas, y una de las líneas prioritarias de investigación traslacional en todo el mundo, evitando los problemas de rechazo inmune de los homotrasplantes, las complicaciones inherentes a la implantación de otros materiales aloplásticos, las secuelas estéticas o funcionales de las zonas donantes de los autotrasplantes de mayor morbilidad, y los problemas éticos del uso de células madre embrionarias.

El cirujano plástico tiene un papel protagonista tanto en la extracción del injerto de células madre del abdomen mediante una liposucción manual tumescente, como en la aplicación clínica rápida sobre distintos defectos, deformidades o pérdidas de sustancia.

Presentamos el protocolo de extracción y procesamiento de células madre derivadas del tejido adiposo (ADSC) aprobado por el Comité Ético de Investigación Clínica, que resulta ser factible, seguro y reproducible, pudiendo servir de guía de actuación para el diseño de nuevos estudios clínicos controlados sobre la eficacia del autotrasplante de células madre aplicados a muchas otras patologías en el universo de la Cirugía Plástica en el que esté comprometida la cicatrización.
Palabras clave Tejido adiposo,
Lipoinfiltrado, Células madre.

Código numérico 19-104-15841

\begin{abstract}
Adult stem cells-based therapy represents the most innovative treatment to regenerate the pathologic tissues (absent or lacking), to "replace like with like" as an aesthetic filler for a variety of cosmetic and reconstructive indications, and is one of the trending translational research lines all over the world; avoiding the host immune response and implant rejection problems of the human allotransplants, the inherent complications due to the implantation of alloplastic materials, the functional and aesthetic secuelae of donor sites in high morbidity autotrasplants, and the bioethical problems with the use of embrionary stem cells. Plastic surgeon has a relevant role such in the extraction of the cellular graft from the abdomen by means of a tumescent manual liposuction, as in the quick clinical application to different defects, deformities and losses of substance. The protocol of extraction and processing of adipose derived stem cells (ADSC) approved by the Clinical Researching Ethical Committee is presented as a feasible, safe and reproducible guide for the design of new controlled clinical studies about the efficacy of the stem cell autotrasplants for the treatment of many pathologies inside the universe of plastic surgery in which scarring process is compromised.
\end{abstract}

$\begin{array}{ll}\text { Key words } & \text { Adipose tissue, } \\ & \text { Lipofilling, Stem cells. }\end{array}$

Numeral Code 19-104-15841

\footnotetext{
* Facultativo Especialista de Área. Unidad de gestión clínica de Cirugía Plástica Reconstructiva. Hospital Universitario Marqués de Valdecilla, Santander. España.

** Catedrático de Histología. Departamento de Anatomía, Histología y Neurociencia. Facultad de Medicina. Universidad Autónoma de Madrid. España.
} 


\section{Introducción}

La Medicina actual y, por ende, la Cirugía Plástica, Reparadora y Estética, se apoya y gira en torno a procedimientos "salvavidas" de trasplantes del mismo individuo (autotrasplante) o de distintos individuos de la misma especie (homotrasplante). Los avances en la conservación y transporte de órganos, los nuevos medicamentos inmunosupresores e inmunomoduladores, el perfeccionamiento del instrumental y de los materiales quirúrgicos, y la depuración técnica de manos especializadas, apoyadas en la microcirugía, ha permitido que sean habituales los trasplantes de órganos y tejidos como riñón, hígado, corazón, pulmón, páncreas, intestino, hueso, cartílago, músculo, tendones o piel; de unidades funcionales como extremidades o manos; incluso de unidades estéticas como cara, triángulo orofacial o folículos pilosebáceos. A pesar de los 1643 trasplantes ejecutados en 2011, la demanda aumenta y el 50\% de los pacientes en lista de espera para algún trasplante no acaban beneficiándose del procedimiento.

Ante esta realidad, investigadores y clínicos, han estimulado y potenciado las donaciones humanas, se han realizado muchos estudios de factibilidad y rechazo con xenotrasplantes, pero sobre todo, se ha dirigido el esfuerzo hacia la proliferación y diferenciación de células madre progenitoras, embrionarias o adultas, in vitro e in vivo; y de células madre adultas multipotenciales de médula ósea $(1,2)$, sangre periférica o de tejidos residentes (3-5). El trasplante no sólo tiene que ver con la dicotomía vida/muerte, sino que tiene un impacto crucial en la calidad de vida de los pacientes; incluso se indican trasplantes con finalidad estética además de reparadora, reconstructiva, recuperadora o reemplazadora.

Estamos en una nueva era de la Medicina, que persigue la regeneración de los tejidos biológicos mediante el uso de células madre vehiculizadas por estructuras de soporte (matrices o moldes reabsorbibles o biodegradables) y estimuladas por moléculas bioactivas como los factores de crecimiento $(6,7)$. Estos tres son los componentes integrantes de la ingeniería tisular, que pueden representarse en un triángulo equilátero, interactuando continuamente entre sí. De los tres, en muchos aspectos las células son el paso crítico o limitante de la triada regenerativa, pues a diferencia de matrices, proteínas y moléculas, no pueden manufacturarse y deben ser extraídas, purificadas y replicadas sin alterar su potencial terapeútico, en suficiente cantidad, antes de su aplicación clínica.

De la misma manera, esta ciencia implica la colaboración multidisciplinaria de biólogos, bioquímicos, científicos de biomateriales y clínicos. Por sus conocimientos en Biología de los trasplantes, anatomía quirúrgica y estructura y función del tejido adiposo, por su capacidad técnica para la extracción mínimamente invasiva de injertos de diversos tipos y lugares, y por la posible rápida aplicación clínica en muchos casos de reconstrucción y de estética (trasplante celular, injerto celular, relleno celular, adhesivo celular), el cirujano plástico debe reclamar su papel protagonista en este terreno (8).

La fuente de células para ingeniería tisular depende de los requerimientos de la estructura que va a ser regenerada. Las células madre embrionarias son pluripotenciales y se aíslan de la masa interna de los blastocistos. Aunque conservan gran capacidad de diferenciación, tienen algunos problemas que deben ser resueltos antes de su aplicación clínica: cultivo celular sin exposición a proteínas animales, desarrollo potencial de tumores hamartomatosos y teratomas, y rechazo inmunológico por parte del huésped. Actualmente, las células madre adultas retienen todavía un grado de multipotencialidad, son más ventajosas para su diferenciación preeminente hacia tejidos de extirpe mesodérmica, como el hueso (interdependencia entre la adipogénesis y la osteogénesis); y se extraen del tejido adiposo unilocular (Fig.1) desde que se demostró que éste es la fuente más abundante de células madre adultas multipotenciales, en numero 10 a 1000 veces mayor que de la médula ósea (9).

La pared abdominal es una zona habitual de depósito graso, dividido en compartimentos superficial y profundo por el sistema fascial circunferencial (Fig.2). Por sus características de rápido acceso, acúmulo graso abundante o suficiente, versatilidad y fácil manejo, y de extracción mínimamente invasiva del tejido adiposo con muy bajo índice de complicaciones y secuelas, el compartimento profundo del tejido celular del abdomen se elige como zona donante ideal del tejido adiposo para aislar las células madre adultas.

\section{Material y Método}

Describimos a continuación de manera detallada el protocolo y método de terapia celular en Cirugía Plástica

\section{Extracción del lipoaspirado}

Después de desinfectar la zona donante con povidona iodada y preparar el campo quirúrgico, se inyecta mepi-

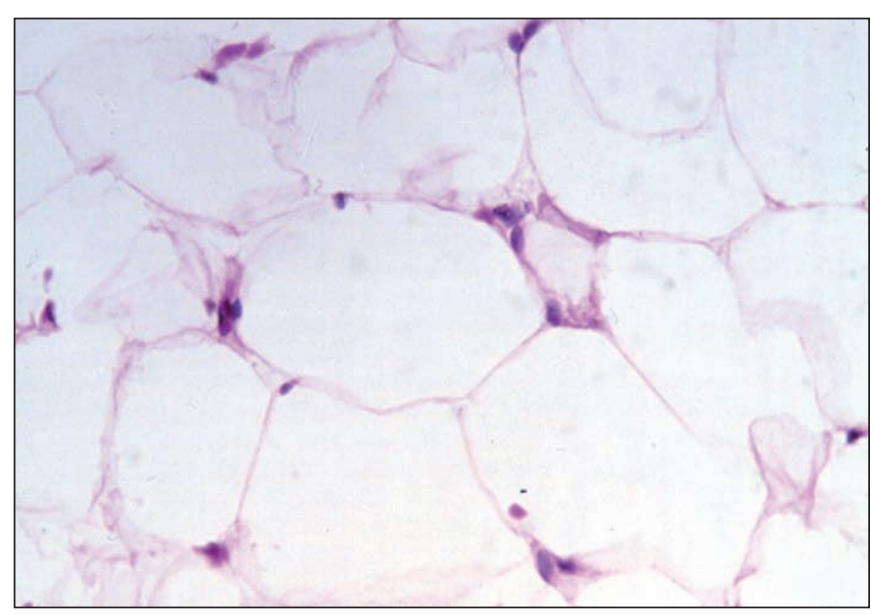

Fig. 1. Tejido adiposo unilocular maduro adulto extraído del abdomen: función metabólica y estructural de soporte mecánico. Contribuye al modelado del contorno corporal. HE 300x. 

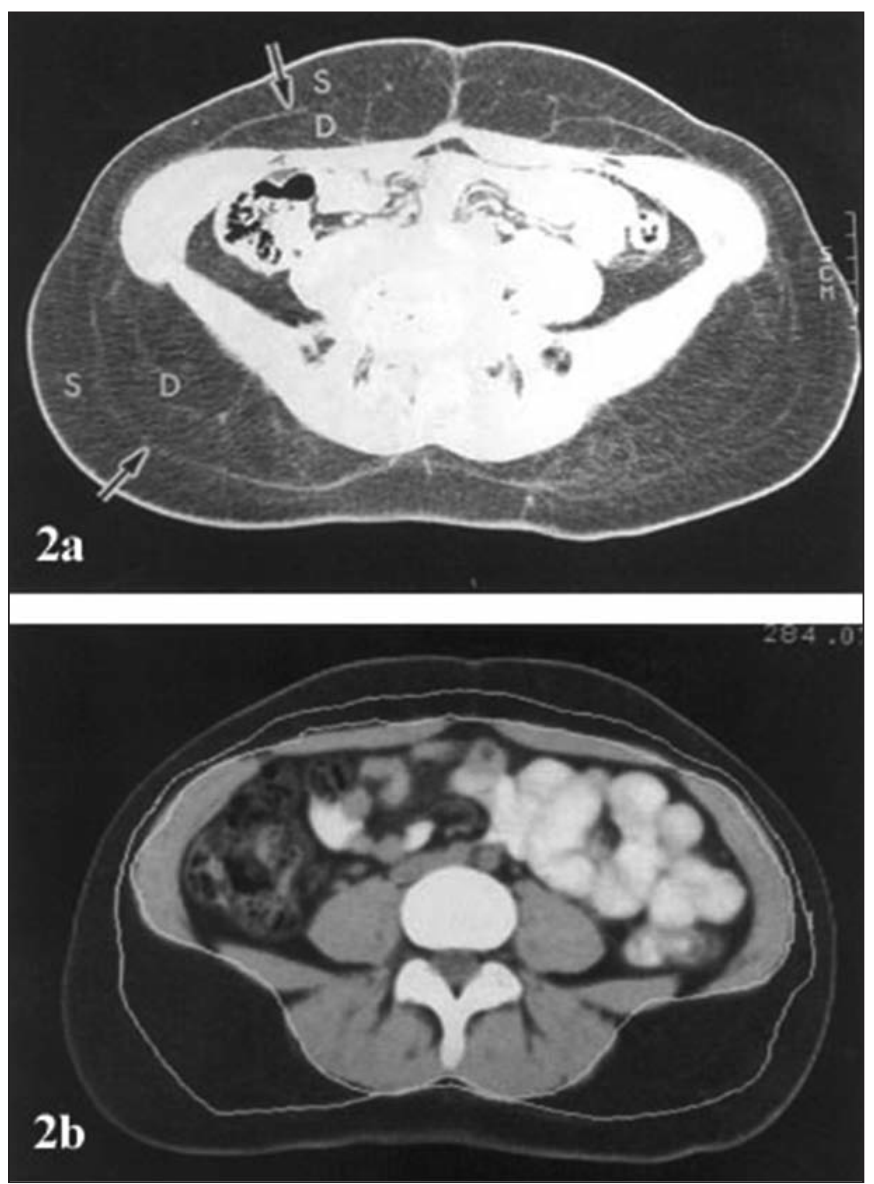

Fig. 2. Tomografías computarizadas $\sin (2 a)$ y con contraste (2b), en las que se aprecian los compartimentos abdominales de grasa superficial (S) y profundo (D), separados por el sistema fascial circunferencial (flechas).

vacaína al $1 \%$ en la piel umbilical inferior para incidir luego $3 \mathrm{~mm}$ con hoja de bisturí del $\mathrm{n}^{\circ} 11$. Se practica una liposucción manual tumescente con fórmula anestésica de Klein modificada (500mg lidocaína 5\% + 12,5 meq de $\mathrm{H} 2 \mathrm{CO} 3 \mathrm{Na}+1 \mathrm{mg}$ de adrenalina 1:100.000 en 1 litro de Ringer Lactato frío), mediante cánulas perforadas con varios orificios, de 3 y $4 \mathrm{~mm}$ de diámetro y distinto diseño, conectadas a jeringas de $50 \mathrm{~cm}^{3}$ en las que se practica vacío con freno. La disrupción mecánica de los lobulillos de tejido adiposo en el espesor del compartimento profundo del hemiabdomen inferior permite obtener un lipoaspirado (Fig.3), que se trasvasa a tubos de laboratorio de $50 \mathrm{~cm}^{3}$, llenando únicamente $20 \mathrm{~cm}^{3}$ de su capacidad.

\section{Procesamiento del lipoaspirado}

TRATAMIENTO FÍSICO: se rellena el tubo de laboratorio con igual volumen de suero fetal bovino (10) (Fig.4), se agita y se centrifugan los tubos a 3000 revoluciones por minuto (rpm) (900g) durante 2 minutos. Se obtiene un centrifugado con 3 capas diferenciadas. Superior: adipocitos rotos, ácidos grasos libres y triglicéridos, que se elimina mediante capilaridad. Inferior: solución salina, anestésico local y células hemáticas, que se desechan mediante drenaje gravitacional. Y capa media: tejido adiposo purificado, con su parénquima (adi-

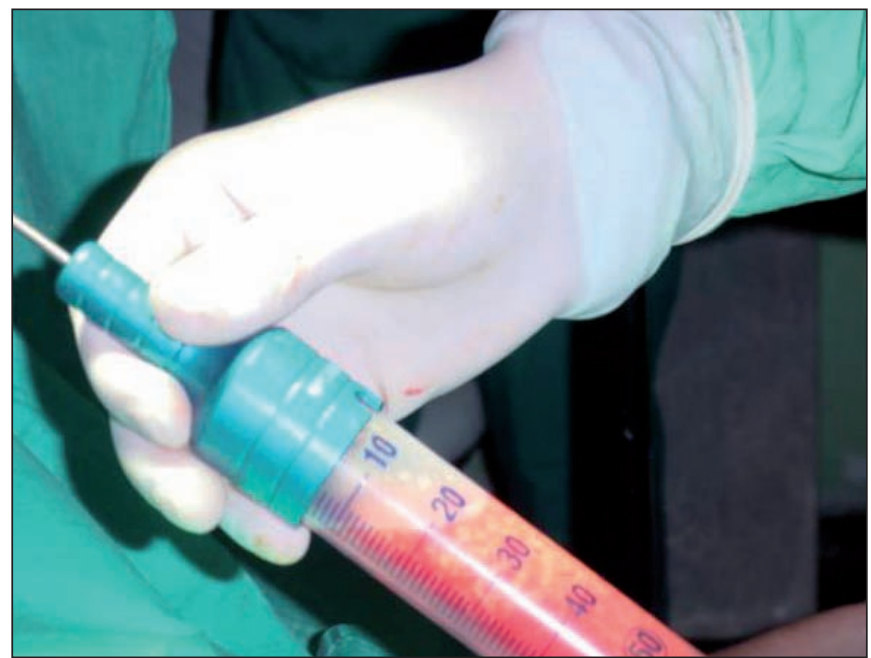

Fig. 3. Liposucción tumescente manual del compartimento profundo del abdomen.

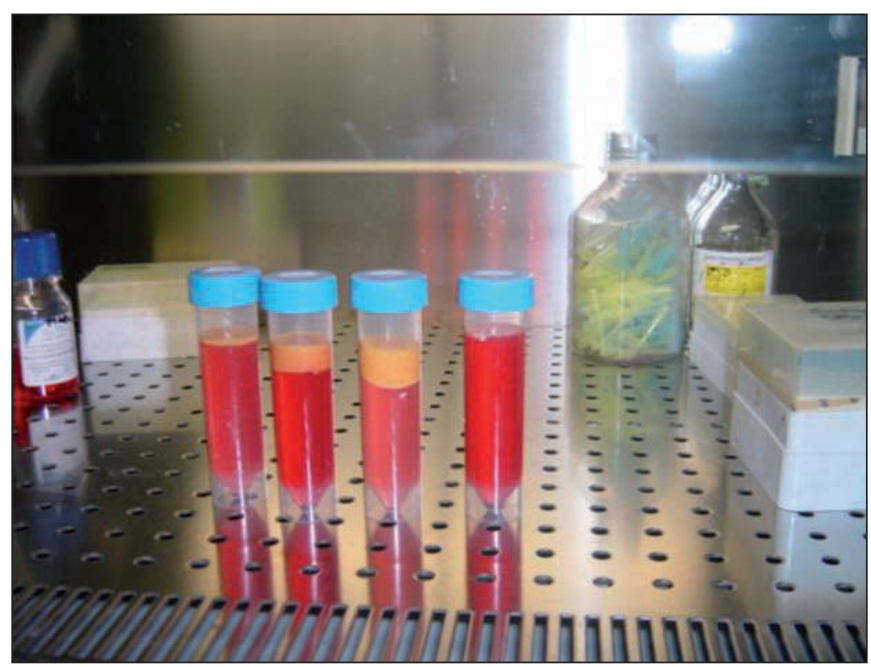

Fig. 4. Relleno de los tubos con igual volumen de suero fetal bovino, que serán agitados y centrifugados a $3000 \mathrm{rpm}$ durante 2 minutos.

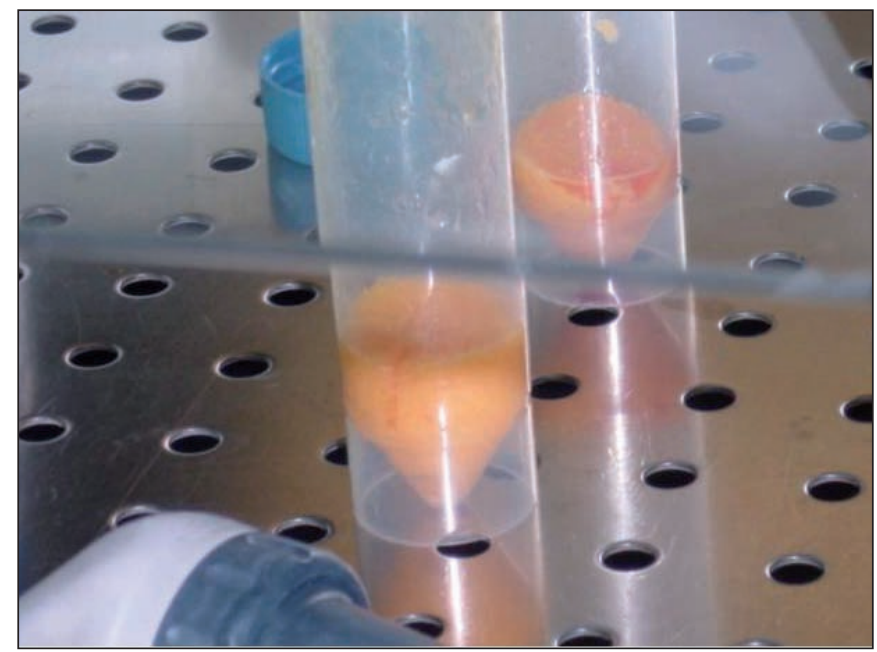

Fig. 5. Tubo de laboratorio con tejido adiposo purificado después de eliminar la capa superior del centrifugado (adipocitos rotos, ácidos grasos libres y triglicéridos) por capilaridad y el estrato inferior del centrifugado (líquido anestésico, suero, células hemáticas) por drenaje gravitacional.

pocitos) y estroma (matriz extracelular de tejido fibroso y vasos sanguíneos), cuya intimidad aloja las células madre adultas multipotenciales (Fig.5). 


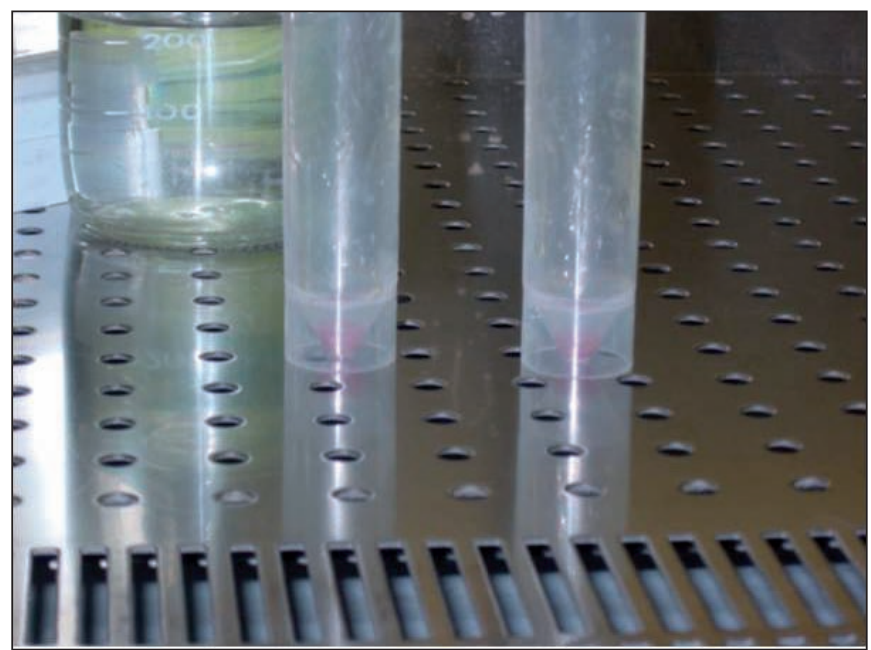

Fig. 6. Tubo de laboratorio con precipitado de alta densidad.

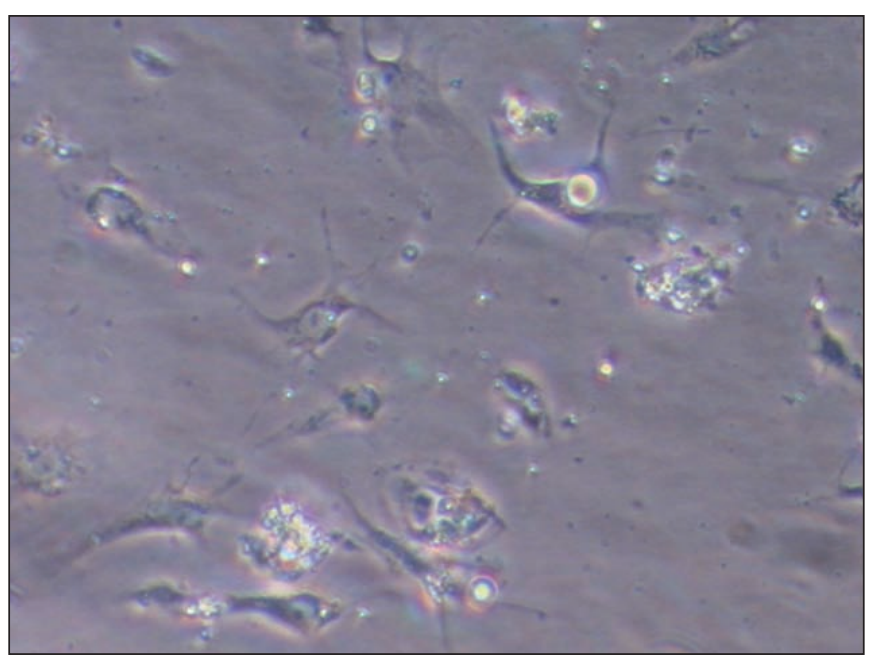

Fig. 7. Incubación inicial: células con ramificaciones y estructuras esferoides que corresponden a restos de grasa. Fotografía en contraste de fase, sin teñir, de cultivo de células madre $300 x$.

TRATAMIENTO ENZIMÁTICO: la matriz extracelular se digiere con colagenasa al 0,075\% durante $30 \mathrm{mi}-$ nutos a $37^{\circ} \mathrm{C}$. Se inactiva después la enzima con igual volumen de medio de cultivo y se centrifuga la mezcla a $250 \mathrm{~g}$ durante 10 minutos. Tras desechar el líquido y grasa indeseables, se obtiene un precipitado de alta densidad proveniente del lipoaspirado (Fig. 6).

TRATAMIENTO QUÍMICO: se resuspende el precipitado en $2 \mathrm{~cm}^{3}$ de cloruro amónico $160 \mathrm{mM}(\mathrm{NH} 4 \mathrm{Cl}) \mathrm{du}-$ rante 10 minutos a temperatura ambiente para lisar los restos de hematíes y se realiza una tercera centrifugación de esta solución a $250 \mathrm{~g}$ durante 1 minuto. Se añade $1 \mathrm{~cm}^{3}$ de medio de cultivo al centrifugado.

\section{Cultivo celular}

Se realiza una incubación inicial del precipitado en medio de cultivo Eagle modificado de Dulbecco, con un $10 \%$ de suero fetal bovino (10) y un $1 \%$ de penicilina y estreptomicina, en condiciones de $37^{\circ} \mathrm{C}$ y un $5 \% \mathrm{CO}_{2}$. En esta fase se aprecian células fusiformes y estructuras esféricas que corresponden a adipocitos residuales (Fig. 7). A las 24 horas se lava el cultivo con suero fetal bovino y las células fijas de la placa se mantienen en el incubador en las mismas condiciones. Cuando el nivel de subconfluencia celular alcanza el $70 \%$, hecho que sucede entre el $5^{\circ}$ y $7^{\circ}$ día (Fig. 8), se incuban las células con tripsina a $37^{\circ} \mathrm{C}$ para disgregarlas, se lavan con suero fetal bovino y se recogen finalmente en $1 \mathrm{~cm}^{3}$ de solución Ringer Lactato.

\section{RESULTADOS}

La Sociedad Internacional de Terapia Celular establece unos criterios rigurosos de comprobación de que realmente las células obtenidas son células madre:

- Adherencia al plástico en 24 horas.

- Morfología fusiforme a las 30 horas (análoga a fibroblasto).

- Verificación de la expresión de más de 95\% de marcadores de células madre mesenquimales provenientes del tejido adiposo mediante citometría de flujo: CD 29, CD 44 y CD 90 positivos; y menos de un 2\% de expresión de marcadores CD 45, CD 34, CD144 y CD106.

- Diferenciación posible a adipocitos, condrocitos y osteoblastos.

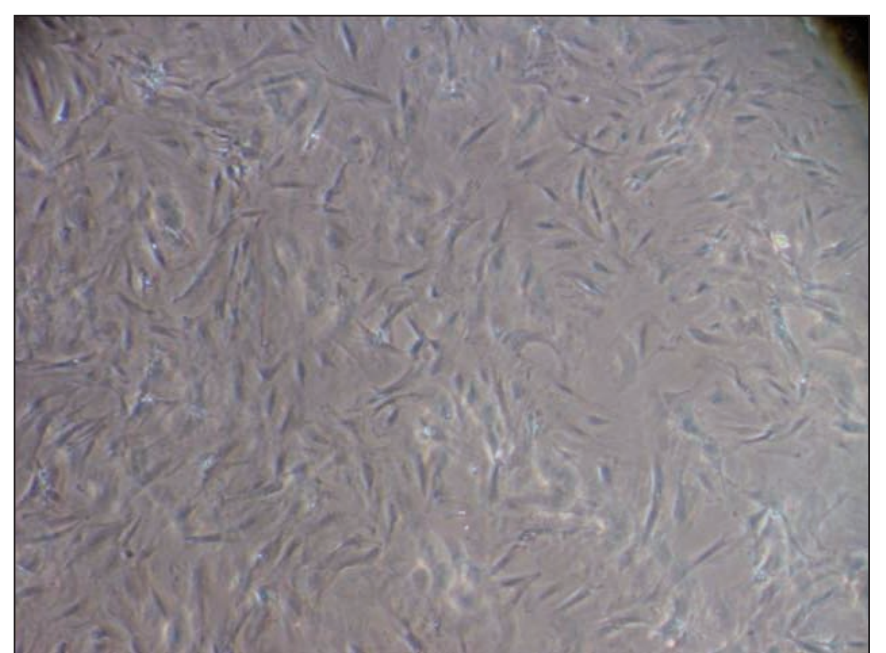

Fig. 8. Nivel de subconfluencia celular cercano al $70 \%$. Fotografía en contraste de fase, sin teñir, de cultivo de células madre 100x.

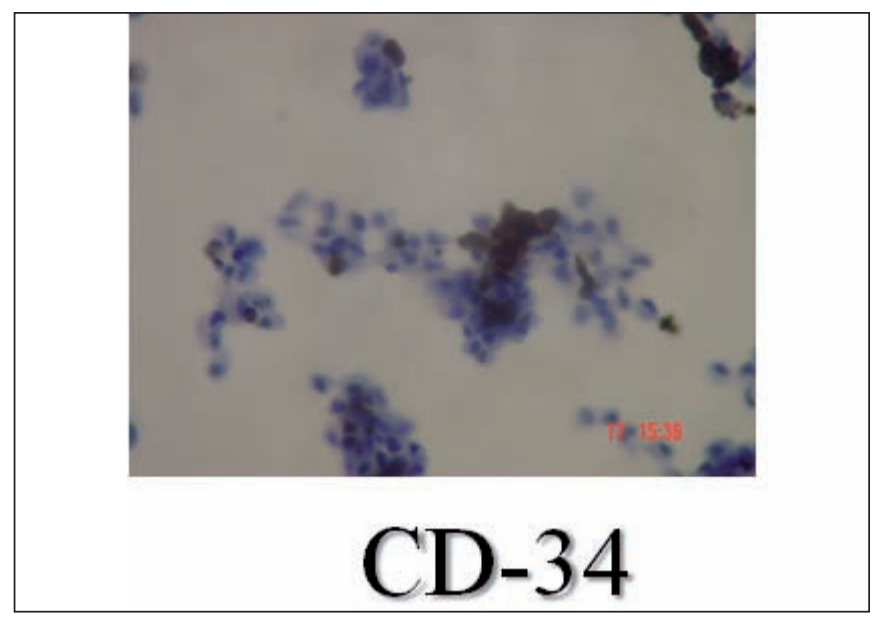

Fig. 9. CD34 +. 


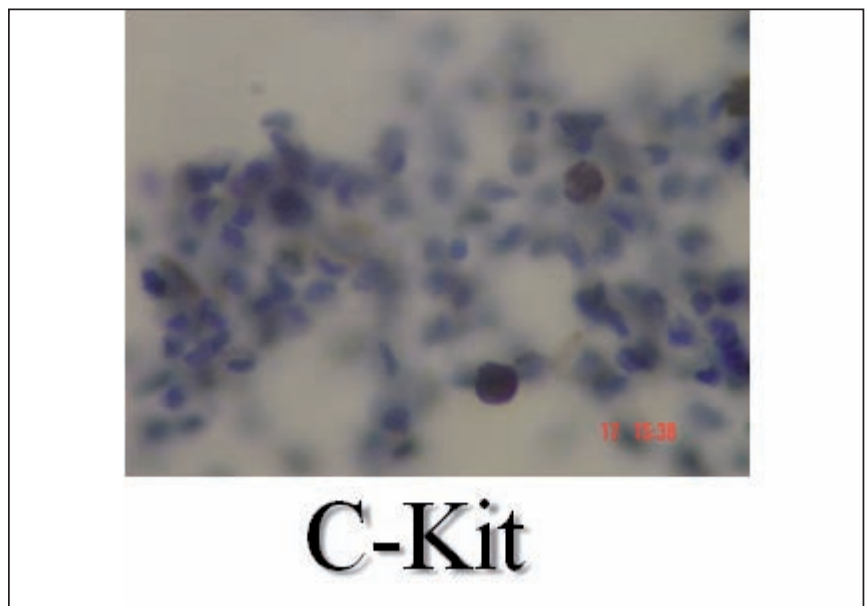

Fig. 10. C-kit+.

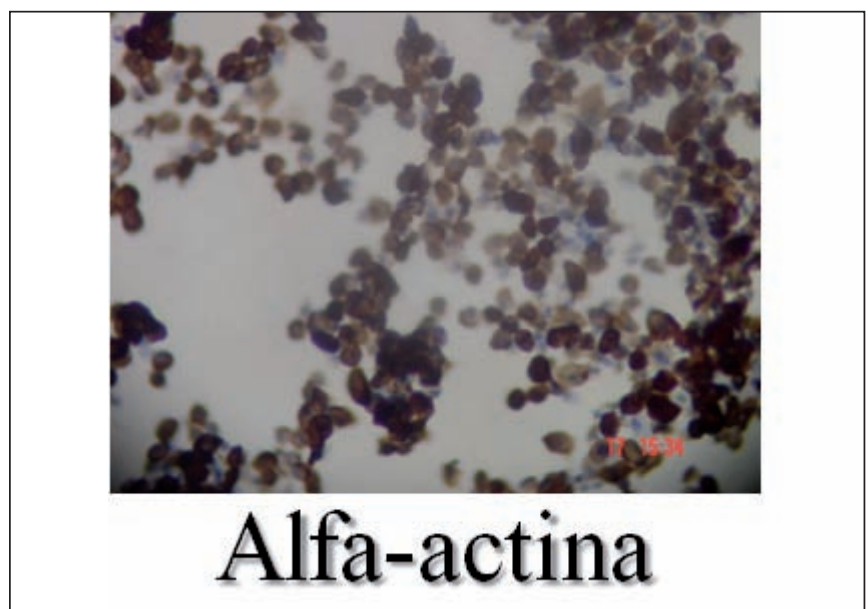

Fig. 11. Alfa-actina + .

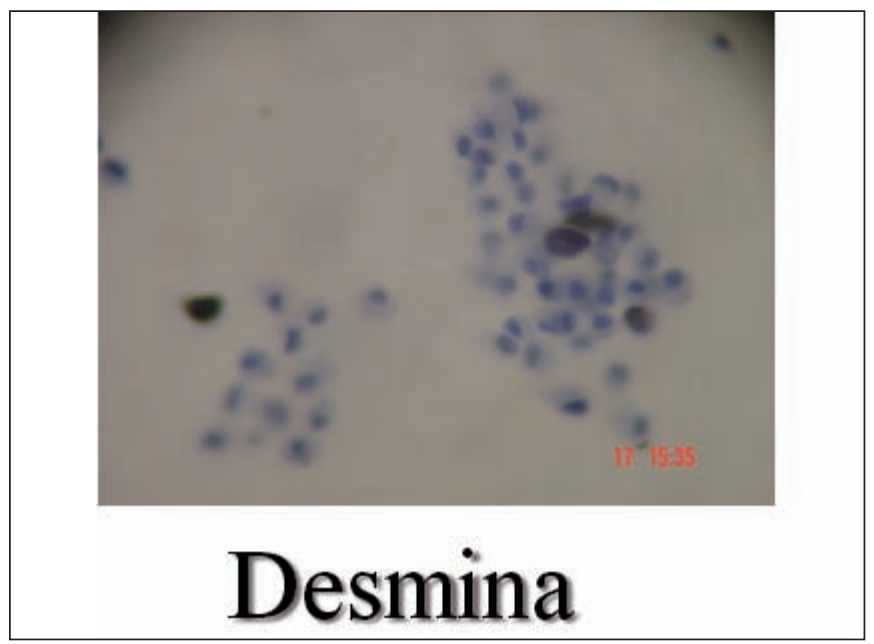

Fig. 12. Desmina +.

La caracterización celular se practicó en conjunción con los departamentos de Anatomía Patológica, Biología Molecular y Farmacología, utilizando técnicas de citometría de flujo, inmunofluorescencia indirecta e inmunohistoquímica. Se obtuvieron los siguientes marcadores celulares positivos: CD34 (Fig.9), C-kit (Fig.10), $\alpha$-actina (Fig.11), desmina (Fig. 12), vimentina (Fig.13), keratina (Fig.14). El marcador de las células melánicas S100 fue negativo (Fig.15).

Otro objetivo de laboratorio en el que se trabaja es la

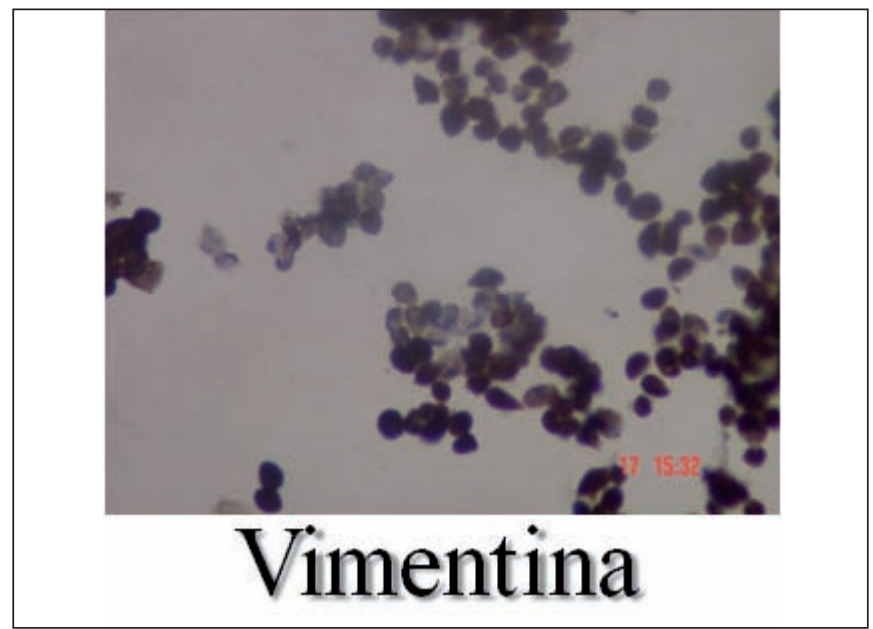

Fig. 13. Vimentina+.

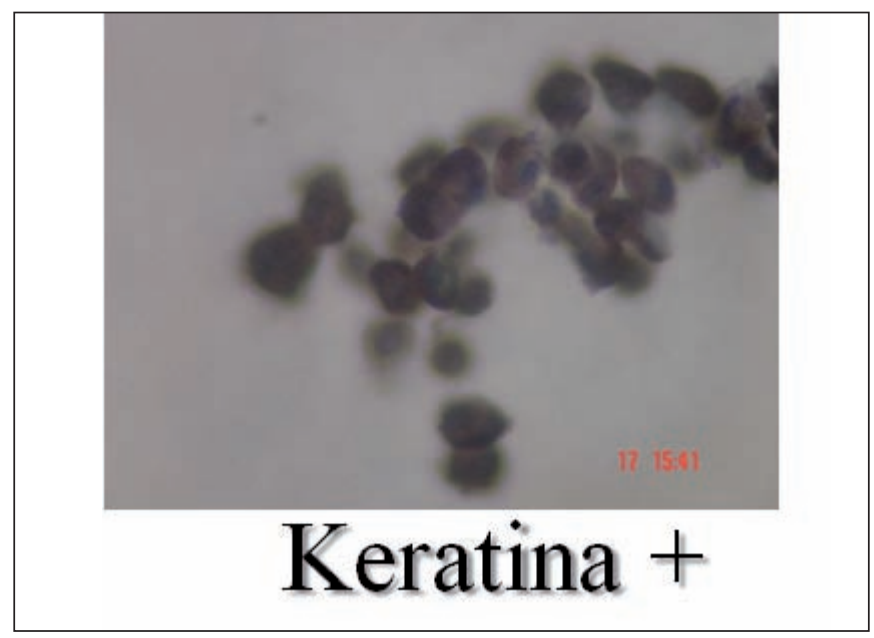

Fig. 14. Keratina +.

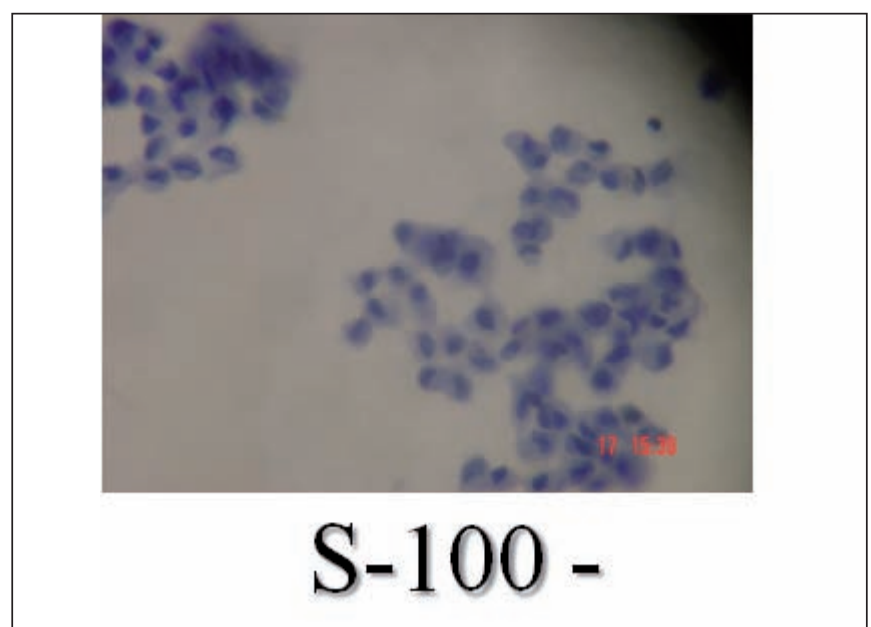

Fig. 15. S100-.

optimización del cultivo de células madre adultas. Para ello, se estudia el ritmo de crecimiento celular en otros medios de cultivo, la evolución de la expresión de marcadores durante el periodo de proliferación y el análisis del efecto de distintos productos biológicos y químicos en las células.

Estas células tienen dos propiedades básicas:

1. A medida que se dividen, tienen el potencial de renovarse y multiplicarse para formar más células madre. El número y plasticidad de células posibles 
para diferenciarse a otros tipos celulares disminuye con la edad.

2. Potencial diferenciador hacia distintos tipos celulares. El cultivo de estas células en medio Eagle modificado de Dulbecco con un $10 \%$ de suero fetal bovino (10) y suplementados con diferentes sustancias, estimula su diferenciación hacia células de extirpe:

- ADIPOGÉNICA: isobutilmetilxantina 0,5mM+ dexametasona $1 \mu \mathrm{M}+$ insulina $1 \mu \mathrm{M}+$ indometacina $200 \mu \mathrm{M}+1 \%$ antibiótico.

- OSTEOGÉNICA: dihidroxivitamina D3 0,1 $\mu \mathrm{M}+$ fosfato 2 ascórbico $50 \mu \mathrm{M}+$ glicerofosfato $10 \mathrm{Mm}+1 \%$ antibiótico.

- CONDROGÉNICA: insulina $6,25 \mu \mathrm{g} / \mathrm{ml}+$ TGFß1 $10 \mathrm{ng} / \mathrm{ml}+$ fosfato 2 ascórbico $50 \mathrm{Nm}+$ $1 \%$ antibiótico.

- MIOGÉNICA: hidrocortisona $50 \mu \mathrm{M}+1 \%$ antibiótico.

- NEUROGÉNICA: ßmercaptoetanol 5-10 mM sin suero fetal bovino.

Demostración objetiva en todas ellas de la multipotencialidad de las células madre adultas provenientes del tejido adiposo abdominal.

\section{Discusión}

En la clínica, se ha probado el uso preliminar de células madre en distintas patologías (11), y se están llevando a cabo numerosos ensayos clínicos en fase III y IV que evalúan la seguridad, factibilidad y reproductibilidad a largo plazo de esta nueva técnica, cumpliendo los estrictos criterios bioéticos. A este respecto la Agencia Española del Medicamento y Productos Sanitarios (AEMPS) recuerda y advierte textualmente que:

- "La oferta directa a ciudadanos y pacientes de distintas terapias basadas en la manipulación de células madre de diferentes orígenes y postuladas para el tratamiento de las más variadas enfermedades y condiciones clínicas está contribuyendo a generar cierta confusión en la sociedad. Se advierte del uso premeditado de determinada terminología médica en situaciones que nada tienen que ver con el tratamiento de enfermedades humanas.

- Con la excepción de los trasplantes de precursores hematopoyéticos, las terapias con células madre utilizadas para el tratamiento de cualquier tipo de enfermedad son consideradas medicamentos $\mathrm{y}$, por tanto, su desarrollo, autorización y utilización debe realizarse de acuerdo con las normas específicas establecidas para este tipo de medicamentos en Europa y España. Hasta la fecha, no hay ningún medicamento basado en células madre que esté comercializado en España, por lo que la oferta de dichos tratamientos fuera de las tres excepciones contempladas: implante de condrocitos autó- logos, queratinocitos para tratamiento de quemados y células troncales limbocorneales para lesiones corneales, y de los ensayos clínicos o el uso compasivo autorizados por la AEMPS, es ilegal.

- En el caso particular de los cosméticos, de acuerdo con la reglamentación, estos productos no pueden contener derivados de origen humano, por lo que la utilización de células madre humanas en productos comercializados es ilegal. Los productos a base de células madre humanas en tratamientos con finalidades estéticas también tienen la consideración de medicamento, por lo que les resultan de aplicación los mismos principios que el resto de tratamientos basados en células madre: demostrar su calidad, seguridad y eficacia en ensayos clínicos adecuados que permitieran al ciudadano saber los efectos y posibles riesgos de su utilización. Hasta la fecha no se ha autorizado ningún medicamento de este tipo con fines estéticos, por lo que su presencia en el mercado se considera igualmente ilegal.

- Los tratamientos que se basan en células madre de origen vegetal no tienen ninguna relación con las células madre de origen humano y no se ha demostrado que posean ninguna utilidad en el tratamiento de enfermedades. No obstante, si así se postulara, sus efectos deberían ser probados en ensayos clínicos adecuados y les resultarían de aplicación los mismos principios. La utilización de este tipo de células en cosméticos u otro tipo de productos para tratamientos estéticos no está relacionada con la prevención, tratamiento o diagnóstico de las enfermedades humanas. La utilización de la misma terminología busca, en muchas ocasiones, aprovechar el aspecto novedoso de las terapias con células madre para trasladarlo a otros ámbitos ajenos al contexto médico".

Este aviso para navegantes delimita en nuestro país actualmente el uso y posibilidades de la Terapia Celular a grupos de investigación traslacional (rápida aplicación clínica) formados por un equipo multidisciplinar ( con cirujano plástico incluido!), dotados de una infraestructura específica y técnicas avanzadas de Biología Molecular y Celular, que trabajan en un Instituto de Investigación vinculado a un Hospital Universitario con un Comité de Ética de Investigación Clinica, y con el apoyo académico, institucional y económico necesarios. El cirujano plástico inmerso en este grupo debe conocer el producto que maneja (células madre mesenquimales provenientes del tejido adiposo), su procedimiento de obtención y procesamiento (liposucción y lipoaspirados) y el productor (institución, patrocinador, departamentos de investigación) (12).

Otra estrategia para uso clínico desde un abordaje de ingeniería tisular es la conjunción de células madre estimuladas por ciertas sustancias químicas y vehiculizadas 
mediante una matriz o molde, intentando fabricar un implante neoadiposo: enriquecimiento con células madre adultas para mejorar la supervivencia de los injertos de grasa, al favorecer la angiogénesis y minimizar la respuesta inflamatoria (13), o su combinación con ácido poliláctico o con colágeno frente a esponjas de ácido hialurónico. Sin embargo, son necesarios más estudios para avanzar en el conocimiento de las señales íntimas implicadas en la diferenciación celular, las interacciones entre las células y la matriz, y de la biología de los morfogenes relacionados con el tejido adiposo (14).

\section{Conclusiones}

El tejido adiposo abdominal es la fuente más abundante y accesible de células madre mesenquimales, por su fácil y rápida disponibilidad y su aplicación clínica con muy baja morbilidad. En aplicaciones clínicas preliminares y ensayos de investigación, los "injertos" de células madre han originado un proceso de cicatrización progresiva efectiva, sin observarse fenómenos de rechazo ni de proliferación celular incontrolada; aunque se requiere un seguimiento a largo plazo del comportamiento de las células y su efecto en determinadas patologías clínicas.

El protocolo de investigación presentado es seguro, factible y reproducible; puede servir de guía central y es perfectamente extrapolable, implantable y asimilable por otros grupos. Pero cada uno debiera trabajar y crecer sobre su propio método y modificaciones; buscar y ensayar sus propias aplicaciones clínicas en el relleno, cobertura, obliteración o cicatrización de múltiples defectos, y realizar su análisis y comprobación objetiva de los resultados obtenidos según Medicina Basada en la Evidencia.

Llegado el momento en que la colaboración del cirujano plástico en cada grupo de investigación sea habitual y dé sus frutos clínicos, estamos convencidos de que el título de nuestra especialidad será Cirugía Plástica, Estética y Regenerativa.

\section{Dirección del autor}

Dr. Eduardo Serna Cuéllar

Unidad de Gestión Clínica de Cirugía Plástica

Reconstructiva.

Hospital Universitario Marqués de Valdecilla.

Avenida Valdecilla s/n

39008 Santander, Cantabria, España

e-mail: eduardoserna7@msn.com
Bibliografía

1. Krause DS, Theise ND, Collector MI, Henegariu O, Hwang S, Gardner R, Neutzel S, Sharkis SJ.: Multiorgan, multi-lineage engraftment by a single bone marrow-derived stem cell. Cell 2001; 105: 369-377.

2. Abkowitz JL.: Can human hematopoietic stem cells become skin, gut or liver cells?. N. Engl. J. Med. 2002; 346: 770-772.

3. Zuk PA, Zhu M, Mizuno H, Huang J, Futrell W, Katz AJ, Benhaim P, Lorenz HP, Hedrick MH.: Multilineage cells from human adipose tissue: implications for cell-based therapies. Tissue Eng. 2001; 7: 211-228.

4. Mizuno H, Zuk PA, Zhu M, Lorenz HP, Benhaim P, Hedrick MH.: Myogenic differentiation by human processed lipoaspirate cells. Plast. Reconstr. Surg. 2002; 109: 199-209.

5. Taylor DA.: Cellular cardiomyoplasty with autologous skeletal myoblasts for ischemic heart disease and heart failure. Curr. Control Trials Cardiovasc. Med.2001; 2: 208-210.

6. Serra Renom JM, Muñoz del Olmo JL. Gonzalo Caballero C.: Uso de factores de crecimiento plaquetar unidos a injertos de grasa para lipofilling facial en ritidectomía. Cir. plást. iberolatinoam. 2006; 32(3): 191197.

7. Sándor GKB.: Tissue engineering of bone: Clinical observations with adipose-derive stem cells, resorbable scaffolds and growth factors. Ann. Maxillofac. Surg. 2012; 2: 8-11.

8. Sterodimas A, De Faria J, Correa WE, Pitanguy I.: Tissuue Engineering in Plastic Surgery. Ann. Plast. Surg. 2009; 62(1): 97-103.

9. Almeida KA et al.: Fracción vascular estromal de tejido adiposo: cómo obtener células madre y su rendimiento de acuerdo a la topografía de las áreas donantes: estudio preliminar. Cir. plást. iberolatinoam. 2008; 34(1): 15-30.

10. Baptista L, Silva K, Pedrosa C, Borojevic R.: Processing of lipoaspirates samples for optimal mesenchymal stem cells isolation. En: Advanced techniques in liposuction and fat transfer (Serdev N). Ed. InTech 2011: 181-202.

11. García-Olmo D, García-Arranz M, Gómez García L, Serna Cuéllar E, Fernández Blaco I, Asensio Prianes L, Rodríguez Montes JA, Lima Pinto F., Herreros Marcos D, García-Sancho L.: Autologous stem cell transplantation for treatment of rectovaginal fistula in perianal Crohn's disease: a new cell-based therapy. Int. J. Colorectal Dis.2003; 18: 451-454.

12. Benito Ruiz J.: Injertos de tejido adiposo: variables que influyen en la viabilidad del adipocito y de las células madre mesenquimales. Cir. plást. iberolatinoam. 2011; 37(4): 311-318.

13. Kuehnle I, Goodell MA: The therapeutic potential of stem cells from adults. BMJ 2002 (325): 372-376.

14. Moseley TA, Zhu M, Hedrick MH.: Adipose-Derived Stem and Progenitor Cells as fillers in Plastic and Reconstructive Surgery. Plast. Reconstr. Surg. J.2006; 1 suppl: $121-128$. 